\title{
ESPACIOS TEMPORALES PARA LA LITURGIA ¿EVOLUCIÓN TIPOLÓGICA O DISOLUCIÓN IDENTITARIA?
}

Data recepción: 2009/09/14

Data aceptación: 2010/04/30

Esteban Fernández Cobián

Contacto autor: efcobian@gmail.com

Universidade da Coruña

\section{RESUMEN}

Este artículo gira en torno a una pregunta: los nuevos espacios temporales para las concentraciones litúrgicas masivas, ¿responden a una evolución tipológica del espacio de culto o, por el contrario, a la disolución identitaria de la arquitectura sacra? Partiendo de la base de que la evolución de la arquitectura es verdaderamente significativa cuando responde a razones programáticas, se analizan los espacios de culto al aire libre, introduciendo los paradigmas de espacio centrífugo y espacio centrípeto, se aborda la relación entre la liturgia y la naturaleza entendida como paisaje, para concluir reivindicando el simbolismo litúrgico como medio de control sobre las nuevas formalizaciones del espacio sagrado.

Palabras clave: Arquitectura, Arquitectura religiosa, Espacio, Espacio de culto, Liturgia

\section{ABSTRACT}

This article focuses on a single question, the issue of whether new temporary spaces for large liturgical gatherings respond to a typological development of the space for worship or, conversely, to the loss of the identity of sacred architecture.

Taking as our basis the assumption that the development of architecture is truly meaningful when it responds to programmatic factors, we analyse outdoor worship spaces, introducing the paradigms of centrifugal space and centripetal space, and look at the relationship between liturgy and nature understood as a landscape, before concluding by upholding liturgical symbolism as a means of controlling new formalisations of sacred space.

Keywords: Architecture, Religious architecture, Space, Worship space, Liturgy

La arquitectura se encuentra en continua evolución. Y aunque los motivos más evidentes pueden ser los estéticos o los constructivos, esta evolución es verdaderamente significativa cuando responde a innovaciones programáticas. Con la arquitectura religiosa ocurre lo mismo. Sus evoluciones más importantes han estado ligadas a nuevas formas de evangelización. Por eso, si nos preguntamos cómo será la arquitectura religiosa del futuro, deberíamos mirar hacia los usos que están generando nuevas necesidades espaciales. Uno de los ejemplos más claros lo constituyen los espacios temporales para las concentraciones masivas de carácter litúrgico.

Apenas existen estudios que se hayan ocupado de este tema, exceptuando algún artículo aislado de carácter descriptivo'. Creo haber sido el primero en abordar su problemática en el libro «El espacio sagrado en la arquitectura española contemporánea»². En ese sentido, este texto quiere ser una continuación de lo que allí se dijo, profundizando en las consecuencias que la proliferación de estos espacios puede tener para la arquitectura religiosa. La pregunta se podría formular así: ¿responden a una evolución consciente del edificio de culto o, por el contrario, suponen su disolución tipológica e identitaria?

\section{Los espacios temporales para la liturgia}

La intensa actividad pastoral desplegada por el papa Juan Pablo II durante su pontificado 
generó una colección de arquitecturas efímeras repartidas por todo el mundo. Estas estructuras provisionales, si bien ya habían sido utilizadas ocasionalmente con anterioridad —en los congresos eucarísticos, por ejemplo-, gracias a la frecuencia de su uso, han acabado por definir un nuevo tipo constructivo: el altar temporal (Fig. 1). Tipológicamente hablando, un altar temporal no es más que un estrado sobre el que se coloca un presbiterio que habitualmente, por estar al aire libre, está cubierto con una suerte de baldaquino. Esta plataforma se sitúa ante una explanada donde se disponen, más o menos ordenados, los asistentes a la celebración. Para optimizar el espacio, bajo el estrado se acomodan los servicios auxiliares, tanto los referentes al culto como los vinculados con los medios de comunicación. Con frecuencia, estas ceremonias son seguidas no sólo en directo, sino también a través de la televisión, y por eso, el dispositivo suele reflejar de manera plástica el evento que se celebra. El mensaje ha de ser rotundo, casi publicitario, y para ello se recurre a la metáfora.

Veamos algunos ejemplos de esta dimensión comunicativa de la arquitectura efímera. Un caso paradigmático se dio en la ciudad de Maceió, en el altar que Decio Tozzi levantó durante el viaje de Juan Pablo II al norte de Brasil (1991); en aquella ocasión, la parábola evangélica de la red barredera estaba presente de modo explícito en la estructura de la cubierta (Fig. 2)3. Algo parecido había propuesto Lucio Costa para el XXXVI Congreso Eucarístico Internacional, celebrado en Río de Janeiro en 1955; allí se comparaba el altar con la barca de la Iglesia mediante una inmensa vela blanca que se agitaba con el viento, recogiendo el soplo del Espíritu (Fig. 3) ${ }^{4}$. Tres años antes, José Soteras Mauri había construido en Barcelona un altar similar, donde la analogía eucarística era más que evidente (Fig. 4).

Podríamos remontarnos más atrás, pues la Iglesia Católica siempre contempló la posibilidad de celebrar el sacramento de la eucaristía fuera del ámbito del templo, si bien a modo de excepción: así ocurría con las misas de campaña o en las romerías populares. El Código de Derecho Canónico de 1917 distinguía entre lugares de culto remotos - las iglesias y los oratorios- y los próximos es decir, los altares. Aquéllos eran consagrados, y éstos sólo bendecidos ${ }^{5}$. Además, establecía que la prerrogativa del altar portáti llevaba consigo la facultad de celebrar la Santa Misa en cualquier lugar, siempre que éste fuera digno (c. 822) ${ }^{6}$. El privilegio se concedía, bien por derecho, bien por indulto de la Sede Apostólica, aunque el Ordinario local también podía autorizar las celebraciones fuera del templo, siempre que el lugar fuese adecuado y existiese una causa extraordinaria y razonable.

Hay que considerar que, en sentido litúrgico, cuando el altar no es fijo, lo verdaderamente sagrado es el ara, que también se denomina altar portátil o piedra sagrada7. Es ella la que sacraliza el espacio, y cuando ésta se remueve, el espacio pierde su carácter sacro. Así ocurre, por ejemplo, en los altares de los cruceros tradicionales, muy frecuentes en el arco atlántico europeo. En 1929, la Sagrada Congregación de Sacramentos promulgó una instrucción sobre la manera de celebrar las misas al aire libre ${ }^{8}$. Según este documento, el altar se debería cerrar por tres de sus lados formando una especie de pequeña habitación que lo preservara del viento.

Esta indicación de tipo práctico parecía marcar un nuevo camino para la arquitectura sacra. Pero la realidad era muy otra. La vida suele ir por delante de las leyes, y en este caso, la Santa Sede estaba proponiendo como paradigma un fenómeno arquitectónico muy preciso: la arquitectura para la evangelización que los conquistadores españoles habían desarrollado en México durante el siglo $\mathrm{XVI} \mathrm{I}^{9}$. Del mismo modo que las iglesias jesuíticas postridentinas habían resultado de una necesidad pastoral muy concreta -cómo aumentar el espacio de predicación sin perder de vista la geometría ideal del templo-, las capillas abiertas mexicanas también surgieron de una necesidad misionera, en este caso de una evangelización realizada de forma multitudinaria. Como había demasiados fieles para tan pocos predicadores y no existían lugares apropiados para desarrollar ni el culto ni la catequesis, los religiosos empezaron a reunir a los conversos en los patios de las casas, y en ellos surgieron simples altares provisionales resguardados bajo un techo de paja o de madera. Con el tiempo, estas construcciones adquirieron formas permanentes, alcanzando su máximo esplendor entre 


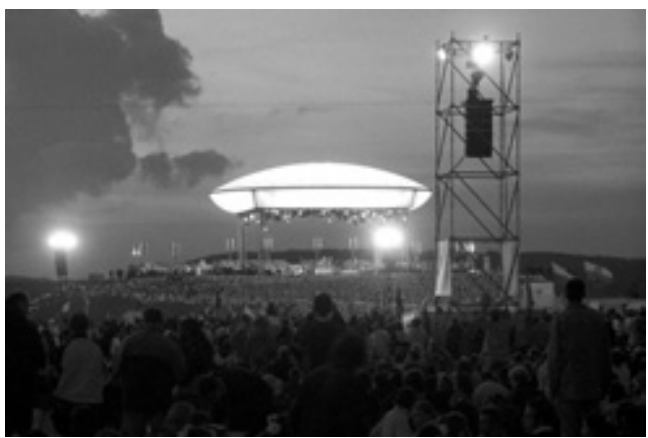

Fig. 1. Josef Rüenauver, altar provisional para la XX Jornada Mundial de la Juventud, Colonia (Alemania), 2005.

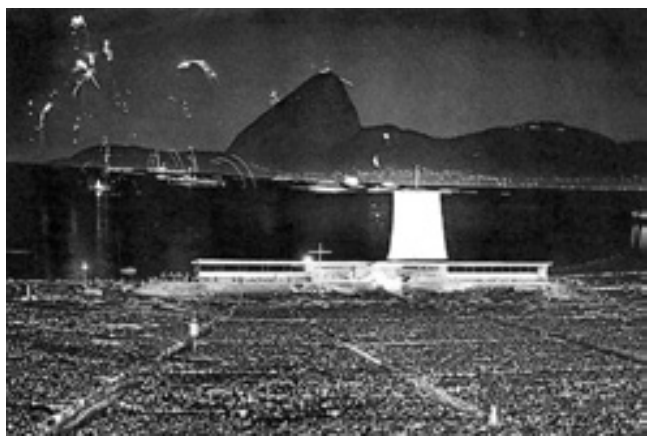

Fig. 3. Lucio Costa, altar provisional para el XXXVI Congreso Eucarístico Internacional, Río de Janeiro (Brasil), 1955.

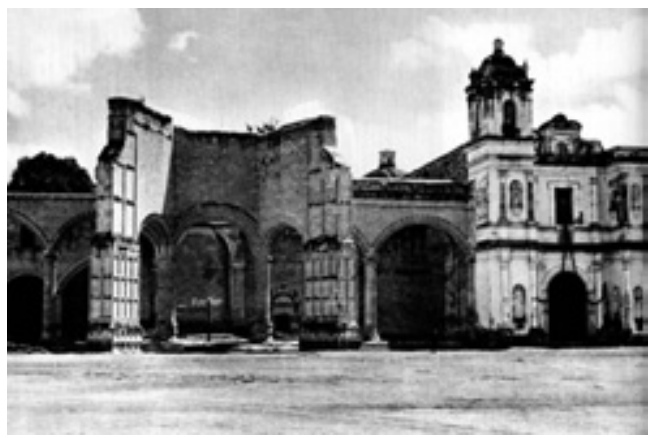

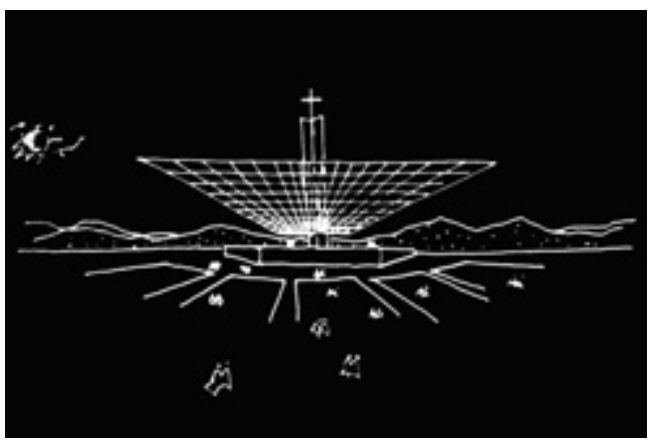

Fig. 2. Decio Tozzi, altar provisional para la visita de Juan Pablo II, Maceió (Brasil), 1991.

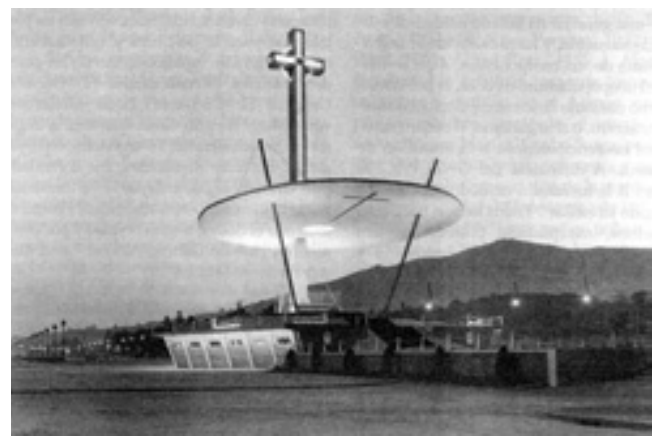

Fig. 4. José Soteras Mauri, altar provisional para el XXXV Congreso Eucarístico Internacional, Barcelona (España), 1952.

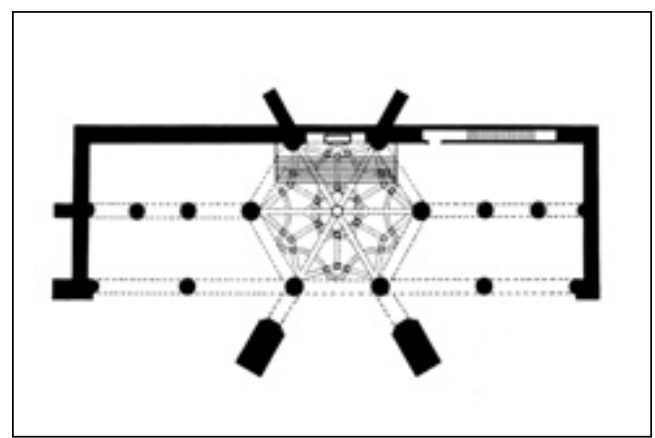

Fig. 5. Capilla abierta del monasterio dominico, Teposcolula (Oaxaca, México), h. 1580. 
1530 y 1580 con las capillas de Coixtlahuaca y Teposcolula (Fig. 5). A partir de esa fecha, la afluencia de nuevos sacerdotes posibilitó la construcción de iglesias convencionales.

La influencia de estas capillas abiertas - la paradoja que supone que una construcción temporal pase a ser permanente sin cambiar su aspecto- se ha dejado notar en la arquitectura moderna, no sólo de México sino también al otro lado del Atlántico, generando piezas tan significativas como la capilla que Félix Candela construyó en Las Lomas de Cuernavaca (1958/ 59) (Fig. 6), la del Sancti Spirit, levantada por Eduardo Torroja en el valle de San Nicolau (Lleida) en 1953 y demolida hace ya algunos años (Fig. 7), o la iglesia de San Pío $X$, realizada a finales de los años cincuenta por Luis Cabrera Sánchez-Real en Santa Cruz de Tenerife (Fig. 8). En los dos primeros casos el uso es eventual, y por consiguiente, no existen límites físicos para el lugar de los fieles, mientras que en el tercero, debido a lo benigno del clima, su uso es permanente, y por lo tanto, una sutil celosía circular acota mínimamente la nave. Pero con celosía o sin ella, estas capillas abiertas plantean un grave problema teórico: ¿dónde empieza y dónde acaba el espacio sagrado?

\section{El problema de los límites físicos del espacio sagrado}

El problema de los límites físicos del espacio de culto cristiano se debatió en España en 1951, durante la Sesión de Crítica de Arquitectura dedicada a la nueva catedral de Madrid. En aquella ocasión, se presentaba un tema que vuelve a estar de actualidad: un espacio religioso con capacidad para veinte mil personas, algo de lo que no existía ningún antecedente histórico conocido. Durante su intervención, el arquitecto Rafael Aburto argumentaba de esta forma la necesidad de construir, no un espacio abierto - lo que hubiera sido mucho más económico-, sino un espacio cerrado: «Después del pecado original Dios maldijo al mundo; por lo tanto, al erigir la casa del Señor necesitamos un espacio cerrado para que su bendición y santificación sean limitadas a su ámbito interior» ${ }^{10}$ (Fig. 9). Aburto proponía aislar completamente el espacio sagrado de un mundo que se entendía como maldito, explicitando una visión dualista y casi maniquea que parecía ignorar algo fundamental para la fe cristiana: la redención universal efectuada por Jesucristo.

Este discurso tenía hondas raíces culturales, ya que uno de los rasgos constitutivos de los templos en todas las religiones es el aislamiento; un aislamiento que históricamente se ha conseguido ubicándolos en el desierto o activando diversos mecanismos arquitectónicos. Paradójicamente, la Iglesia Católica asumió este principio como algo natural, a pesar de que los primeros cristianos sabían que las iglesias no eran las moradas de Dios, sino que Dios habitaba en su propio corazón (Jn 4, 23). Acaso diversas circunstancias derivadas del hecho de que las iglesias también eran espacios de reunión estén en la base de esta clausura. De cualquier manera, hasta el Concilio Vaticano II se sobreentendía que el espacio sagrado implicaba un edificio cerrado, bien porque parecía exigirlo la liturgia, bien porque para consagrar ese ámbito resultaba imprescindible aislarlo de los usos profanos ${ }^{11}$.

En lo que se refiere a la relación del espacio de culto con la naturaleza circundante, para el legislador canónico la iglesia era un lugar ensimismado sin ninguna vinculación óptica con el paisaje. Cuando se entraba en ella se accedía a otra dimensión: a un lugar que, mediante el símbolo y el número, había sido transfigurado físicamente, y que el rito había convertido en un trasunto del paraíso. El simbolismo era particularmente importante y lo impregnaba todo: el de la puerta como tránsito iniciático, el de la nave entendida como itinerario vital, o el del santuario, meta de la vida y umbral del más allá. Este simbolismo era auténtico, lógico y profundo; había ido decantándose durante cientos de años e, incluso, la propia liturgia lo había hecho suyo. La vinculación con la naturaleza se mantenía en este plano, a través, por ejemplo, de la orientación ritual. Por tanto, ¿qué necesidad había de conservar una relación visual con el exterior?

A pesar de que existen numerosos tratados que han estudiado las características simbólicas del edificio sacro a lo largo de la historia' ${ }^{12}$, en los últimos tiempos, este simbolismo casi se ha perdido del todo. Las nuevas iglesias ignoran sus normas, desde la orientación ritual hasta la lógica de la apertura de los huecos en los muros. En ocasiones, estos hechos han generado intensas 

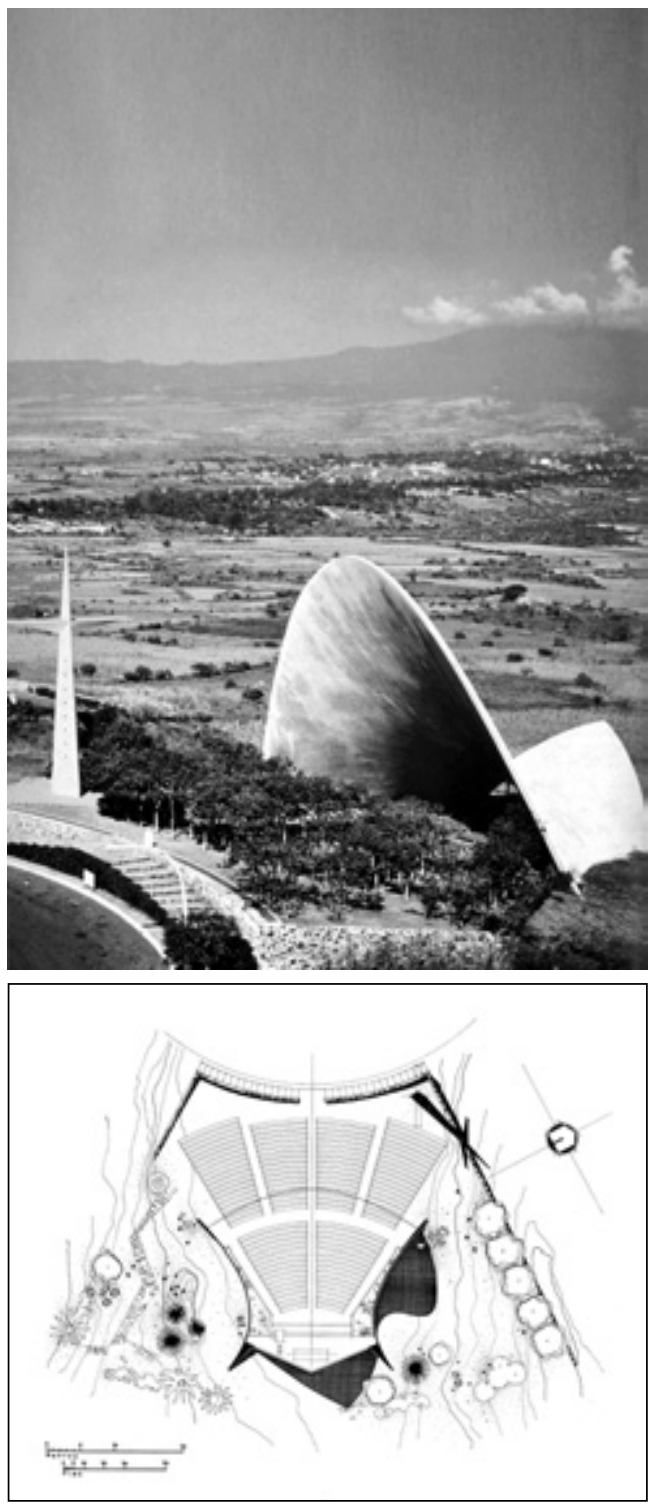

Fig. 6. Félix Candela Outeiriño, capilla abierta, Las Lomas de Cuernavaca (Palmira, México), 1958/59.

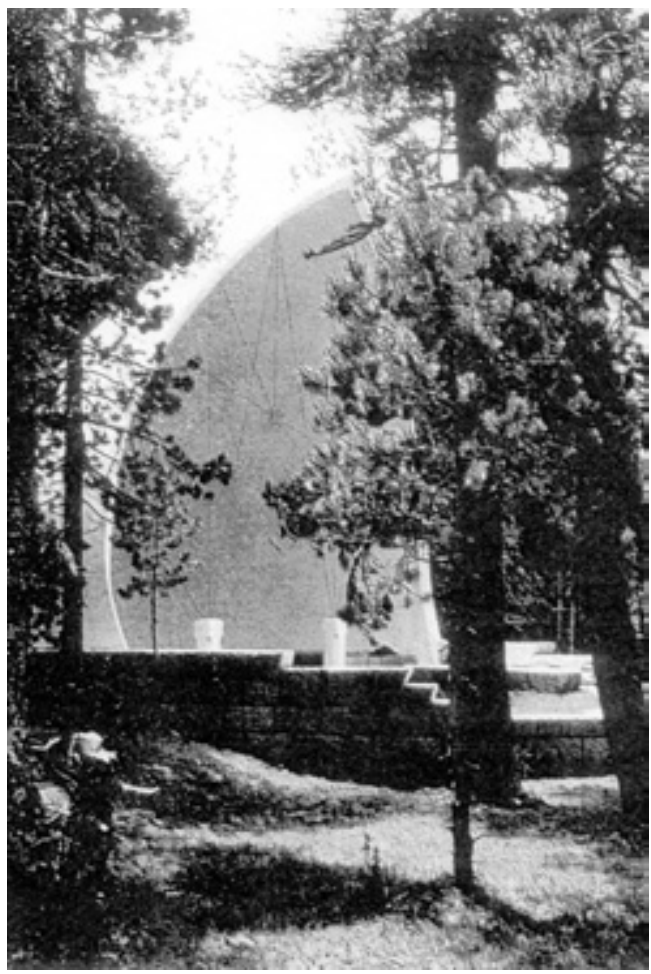

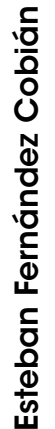

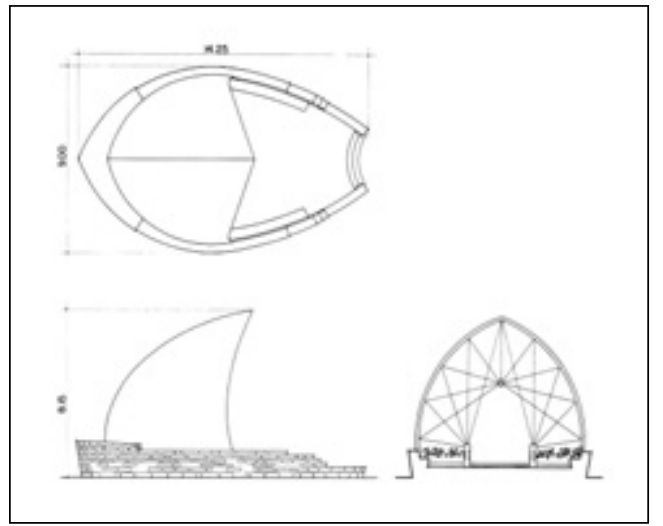

Fig. 7. Eduardo Torroja Miret, capilla abierta del Sancti Spirit, Valle de San Nicolau (Lleida, España), 1953. 
polémicas, como la que hace algunos años suscitó en Portugal la ventana rasgada de la iglesia de Marco de Canaveses (Álvaro Siza Vieira, 1990/98). Lo que se está planteando aquí es un nuevo problema arquitectónico de mayor alcance que el de los límites físicos del espacio sagrado: la relación entre el espacio litúrgico, el simbolismo y la naturaleza. Un problema que, si bien es evidente en los altares al aire libre y en las capillas abiertas, cada vez con mayor frecuencia se está trasladando a los espacios de culto convencionales.

La arquitectura tiene como misión, con respecto a la liturgia, hacerla posible físicamente (...) Dejemos ahora la cuestión del culto al aire libre, que nos llevaría muy lejos, y, por supuesto, fuera de la demarcación de los arquitectos ${ }^{13}$.

Esta afirmación del teólogo español Carlos Castro Cubells, fechada en 1965, deja entrever que a pesar de que los espacios litúrgicos abiertos habían dejado de ser infrecuentes tras el Concilio Vaticano II, los problemas arquitectónicos que se derivaban de ellos —el valor del simbolismo en la arquitectura religiosa, los límites de lo sacro o la relación visual del espacio de culto con la naturaleza - estaban todavía lejos de resolverse. Por eso, pienso que tendríamos que preguntarnos si existió algún apoyo teológico sobre el que se pudo fundamentar el desarrollo espacial de estos espacios de culto - o si por el contrario todo fue fruto de la espontaneidad-, y en su caso, cuándo comenzó su generalización.

El 11 de octubre de 1962, el Concilio Ecuménico Vaticano II se abrió con una solemne ceremonia dentro de la basílica de San Pedro. Sólo tres años más tarde, el 8 de diciembre de 1965, el Concilio se clausuraba al aire libre, en la columnata de Bernini. Más allá de su dimensión mediática, pienso que se trató de un gesto muy significativo — progresista, o como se decía entonces, aggiornatto-. De alguna manera, la Iglesia Católica se abría al mundo, ratificando la doctrina - un tanto oscurecida por el paso de los siglos - de la bondad intrínseca de la creación y, por lo tanto, de su primigenia sacralidad.
Tras el Concilio Vaticano II se produjo un cambio en la espiritualidad cristiana que afectó directamente a la manera de plantear los espacios de culto. Esta mutación consistió en el paso desde una espiritualidad pesimista, parapetada tras sus muros y que veía al mundo como un enemigo, a una espiritualidad optimista y desplegada sobre el entorno, fundamentada en una fuerte presión interior que le permitía entender el mundo como oportunidad ${ }^{14}$. El desplazamiento de estos conceptos teológicos se tradujo de manera inmediata en una desmaterialización de los lugares de culto, tanto en los de la actividad cotidiana de la Iglesia como sobre todo en los utilizados en los grandes eventos eclesiales. En este sentido, me parece muy significativa — por arquitectónica- la siguiente consideración, que pocos meses después de la clausura del Concilio y en el marco de una multitudinaria misa al aire libre en la Universidad de Navarra (España), realizó su Gran Canciller, Josemaría Escrivá:

Reflexionad por un momento en el marco de nuestra eucaristía, de nuestra acción de gracias: nos encontramos en un templo singular; podría decirse que la nave es el campus universitario; el retablo, la biblioteca de la universidad; allá, la maquinaria que levanta nuevos edificios; y arriba, el cielo de Navarra (...) Lo he enseñado constantemente con palabras de la Escritura Santa: el mundo no es malo, porque ha salido de las manos de Dios, porque es criatura suya, porque Yaveh lo miró y vio que era bueno ${ }^{15}$.

Este planteamiento teológico -antiguo, olvidado, ratificado por el Concilio y expuesto aquí por Escrivá con su característica claridadabrió el camino hacia un nuevo tipo constructivo, el altar al aire libre, que pasó de ser algo extraordinario a convertirse en algo habitual.

Algunos años después, el entonces cardenal Joseph Ratzinger recordaba que uno de los objetivos del Concilio Vaticano II había sido superar un cierto conservadurismo eclesial. Pero añadía: «Muchos olvidan que el concepto conciliar opuesto a conservador no es progresista, 


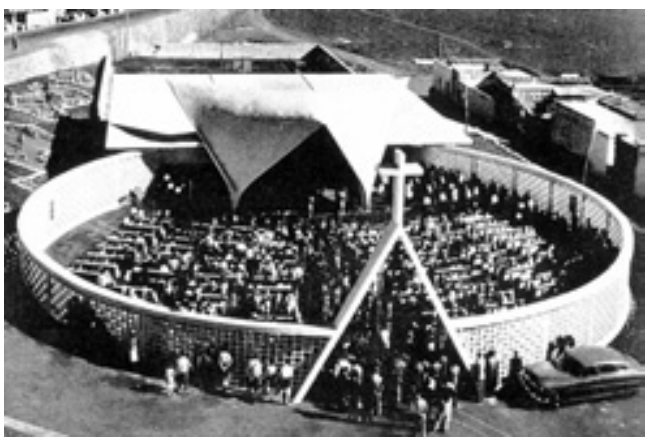

Fig. 8. Luis Cabrera Sánchez-Real, San Pío X, Santa Cruz de Tenerife (España), h. 1958.

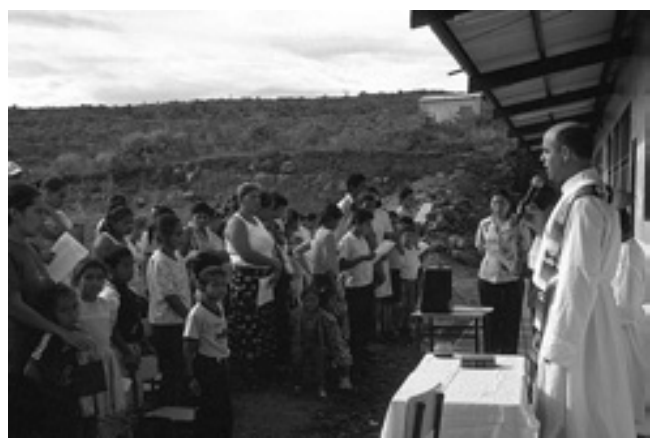

Fig. 10. Espacios provisionales para la celebración litúrgica, Tegucigalpa (Honduras), 2004.

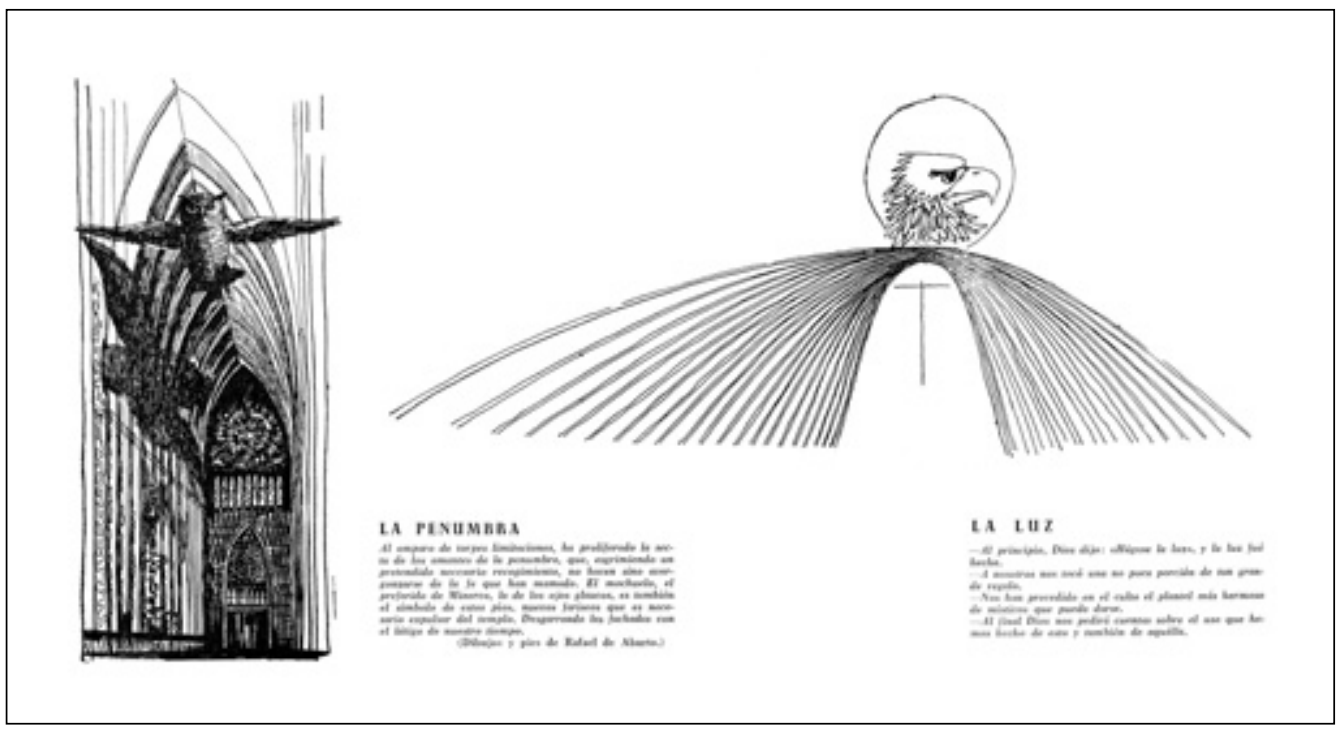

Fig. 9. Rafael Aburto Renobales, La penumbra y la luz. Esquemas para la Sesión de Crítica de Arquitectura dedicada al proyecto de Catedral de Madrid, 1950.

sino misionero» ${ }^{16}$. Me interesa destacar esta frase porque entiendo que la arquitectura sacra no evolucionará ni a partir de la experimentación formal ni a partir de la experimentación litúrgica; ni siquiera a partir de la simbiosis con otras formas de culto que pueden darse en nuestra sociedad. Más bien, pienso que el espacio sagrado del futuro quedará determinado por las peculiares necesidades pastorales que vayan surgiendo en la tarea evangelizadora. Si lo fundamental para la Iglesia Católica es el anuncio y la celebración del kerigma ${ }^{17}$, un garaje, el patio de una escuela o un prado de montaña con un altar protegido del viento pueden ser, en ocasiones, el sitio adecuado para ello (Fig. 10). Otra cuestión muy distinta es que esos espacios lleguen a ser considerados como verdadera arquitectura. 


\section{¿Evolución espacial o disolución tipológica?}

Una vez mostrada la inconsistencia de los argumentos que defendían la clausura esencial del espacio sagrado, hemos de explicar qué es lo que nos lleva a considerar las arquitecturas abiertas como verdadera arquitectura sacra. Para ello, debemos introducir dos nuevos paradigmas espaciales: los de espacio centrifugo y espacio centrípeto.

Como se sabe, la fuerza centrífuga es la que aleja un objeto del centro, en tanto que la centrípeta es la que lo acerca a ese centro. Es conocida la definición - derivada de las reflexiones del filósofo chino Lao-Tse- según la cual la arquitectura no son cuatro paredes sino el aire que queda dentro ${ }^{18}$ : este sería el espacio centrífugo, que otros han denominado estereotómico. Por el contrario, el espacio centrípeto se da siempre alrededor de un núcleo denso. Pensemos por un momento en una hoguera: el espacio varía en razón de su proximidad al fuego, cuyos límites de influencia no están claros. Es más, a una determinada distancia, la pertenencia al espacio de la hoguera deja de ser física para pasar a ser relacional: uno está dentro del espacio si está involucrado en la conversación, en el juego o en el rito; depende de los lazos que haya conseguido crear a su alrededor.

Así como el espacio centrífugo está muy arraigado en la tradición arquitectónica cristiana, el espacio centrípeto, por el contrario, se fundamenta teóricamente en las indicaciones litúrgicas del Concilio Vaticano II. En ellas se determina que el centro de todas las sinergias del culto es el altar —el ara, piedra sagrada o altar portátil, si estamos al aire libre-, y que su fuerza es tal que permite aglutinar personas y objetos a su alrededor prescindiendo de las acotaciones físicas convencionales. Así, podemos afirmar que el paradigma espacial centrípeto hace estallar -o mejor dicho, disuelve - los límites físicos de la arquitectura sacra, y que es el propio poder de la liturgia desarrollada alrededor del ara, el que configuraría los límites del espacio, y no los muros que la envuelven. Nos encontramos, entonces, muy cerca del templo de piedras vivas, tan caro a la tradición teológica paulina. En este sentido, podemos afirmar que las capillas abiertas y los altares al aire libre son una evolución tipológica del edificio eclesial

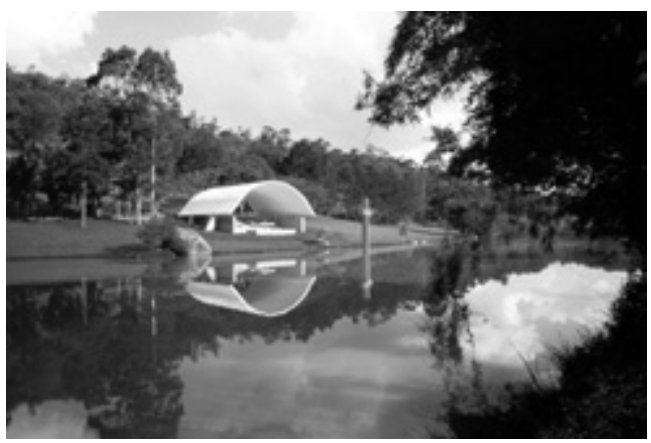

Fig. 11. Decio Tozzi, capilla abierta en la Facenda Veneza, Valinhos (Brasil), 2001/02.

coherente con el redescubrimiento contemporáneo del altar como centro del espacio sagrado.

Llegados a este punto, podemos abordar la segunda parte de la pregunta que nos hacíamos al principio: si esta evolución desmaterializadora del espacio de culto cristiano supone una amenaza para su identidad como tipo.

La disolución de los límites del espacio sacro ya se ha experimentado en algunas de las obras de arquitectura religiosa más celebradas de las últimas décadas, como la Capilla del Politécnico de Otaniemi, de Kaija y Heikki Siren (1957) o la Capilla del Agua, de Tadao Ando (Hokkaido, 1985/88). En estas iglesias, el retablo ha sido sustituido por una visión directa del paisaje exterior, una visión que tiene la cruz como centro focal. Recientemente, la capilla abierta que Decio Tozzi construyó en la Facenda Veneza, cerca de São Paulo (2001/02), ha dado un paso más en este planteamiento, prescindiendo incluso del cierre frontal del presbiterio (Fig. 11) ${ }^{19}$. Gracias a las excepcionales condiciones climáticas y de la propiedad del suelo, el edificio se funde completamente con el paisaje, pero en él la cruz ya no está en el centro, sino en un lateral, y es la naturaleza la que ocupa su lugar.

Podemos observar el progresivo deslizamiento de los conceptos: el sitio hacia donde se ora ya no es una realidad geográfica vinculada a la salida del sol, con todo su simbolismo, ni tampoco un retablo que contiene fragmentos de la historia sagrada, ni siquiera, en último término, 


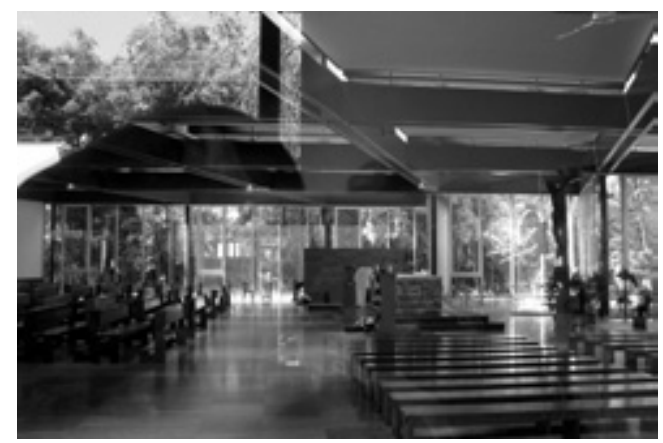

Fig. 12. Filippo Monti, San Vicenzo de Paoli, Bolonia (Italia), $1957 / 60$.

la cruz de Cristo, sino que se trata de la misma naturaleza, de la creación en estado puro.

También existen algunas iglesias que han difuminado sus límites mediante la utilización de un cerramiento completo de vidrio. Es el caso de la iglesia de San Vicenzo de Paoli, que el arquitecto Filippo Monti construyó en Bolonia tras ganar un concurso convocado por la revista Chiesa e Quartiere en $1957^{20}$. Cincuenta años después, sigue gozando de gran aceptación por parte de la comunidad, ya que el espacio interior es muy grato y se enriquece con la vegetación cambiante que lo rodea (Fig. 12). Conviene hacer notar que esta vegetación no forma parte de un paisaje abierto, como en los casos anteriores, sino de una naturaleza doméstica, al igual que ocurre en la capilla de San Pedro que se encuentra en los jardines del Palacio de Boa Vista, en São Paulo (Paulo Mendes da Rocha 1987/88) (Fig. 13).

Pero es en la Setre Chapel (Kobe, 2004/05), donde Ryuichi Ashizawa lleva la desmaterialización al extremo (Fig. 14). La iglesia quiere diluirse, desaparecer, tanto exterior como interiormente. Al exterior, se utilizan resinas para que el hormigón refleje el cielo y las nubes, mientras que en el interior, los paramentos se pulen al máximo para que la luz solar los anule visualmente. Incluso el mobiliario colabora en esa desmaterialización extrema. Pero no nos engañemos: se trata de una transfiguración material, no simbólica; un truco de magia, una

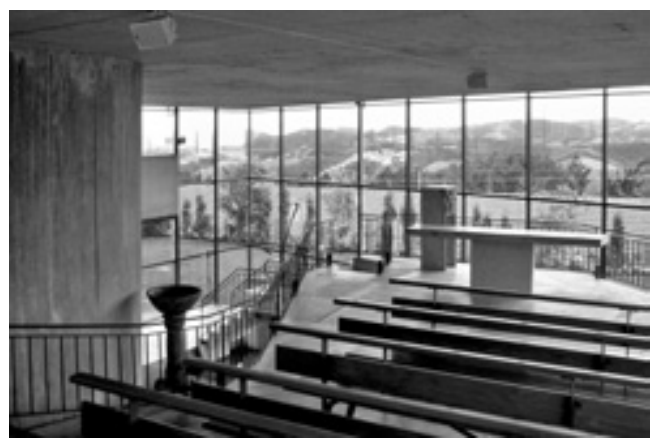

Fig. 13. Paulo Mendes da Rocha, capilla de San Pedro apóstol, Sao Paulo (Brasil), 1987/88.

escenografía. La arquitectura religiosa es otra cosa. No es lo mismo incorporar la naturaleza en el interior del templo de manera abstracta, a través del símbolo o de la imagen, como ocurría tradicionalmente, que incorporarla de manera explícita. En el primer caso se pretende entender un misterio, en el segundo, sólo sentirlo.

Esta necesidad de una mayor inmediatez visual pone de manifiesto varias tendencias de la sociedad contemporánea. En primer lugar, una inquietante disminución del valor simbólico del arte y de la arquitectura, que se encuentran con grandes dificultades para transmitir algo más que su propia materialidad. No nos debería extrañar, por tanto, la falta de confianza mostrada por el pueblo cristiano hacia el arte contemporáneo y sus artífices para acercarse siquiera al nivel medio alcanzado en otras épocas por la arquitectura que ha fundamentado su identidad religiosa, y su reciente apuesta por el paisaje. Pero la reivindicación progresiva de la naturaleza como ámbito de lo sublime también procede de una visión romántica del mundo, donde lo sagrado no es tanto algo razonable —racional_como algo meramente sensible. Por eso resulta esencial encontrar un equilibrio entre el redescubrimiento de la naturaleza como camino de aproximación a Dios — que se refleja, por ejemplo, en la Carta Apostólica Dies Domini de Juan Pablo II (1998)_, y la propia identidad de la iglesia cristiana, que desde tiempos remotos ha utilizado el arte de la arquitectura para filtrar de la 
naturaleza aquello —y sólo aquello— que servía para sus intereses apologéticos.

Tal vez sea posible una adecuada incorporación de la naturaleza domesticada como fondo del espacio de culto, algo que no estaba al alcance de la tecnología constructiva de otras épocas y que, tal vez por ello, no se había llegado a implementar. Así, se podrá satisfacer esa tendencia postromántica de la sensibilidad contemporánea, conjurando cualquier posible deriva hacia el panteísmo o el sincretismo religiosos. Precisamente esa fue la estrategia que se utilizó en uno de los mejores escenarios de las Jornadas Mundiales de la Juventud: el que se planteó en el hipódromo de Longchamp (París, 1997). Allí se definió un perfecto templo al aire libre completamente rodeado por los árboles del Bois de Boulogne 21 .

\section{Hacia una recuperación del auténtico simbolismo arquitectónico}

Hasta aquí, hemos tratado de rastrear qué consecuencias tiene para la arquitectura cristiana la proliferación de los espacios temporales para la liturgia, que si bien responden a una verdadera evolución del espacio de culto, también han provocado en él una cierta disolución identitaria. El discurso nos ha ido llevando desde la identificación del objeto que sacraliza centrípetamente el espacio de culto - el ara o piedra sagrada - hasta la determinación relacional de este mismo espacio y, por lo tanto, no vinculada a ningún cerramiento físico. Sin embargo, la progresiva e inquietante presencia de la naturaleza dentro del espacio sagrado plantea la necesidad de su control. Por eso me gustaría introducir una reflexión final.

En los últimos años, todos los inconvenientes de los espacios temporales para la liturgia se han querido solucionar con los macrotemplos. En estas construcciones el espacio sacro está acotado físicamente y protegido de las inclemencias del clima. Pero todavía existe un problema que no se ha podido resolver: la disolución de su identidad tipológica. ¿Quién consideraría el pro- yecto de catedral en Madrid, de Aburto y Cabrero, como una iglesia? ¿Y la basílica de San Pío X en Lourdes o la reciente iglesia de la Santísima Trinidad en Fátima? (Fig. 15). Todos ellos son edificios tan inmensos que, más que de iglesias, tendríamos que hablar de recintos religiosos que apenas se distinguen de los espacios al aire libre. Se podría argumentar que jurídicamente son iglesias, pues como tales han sido consagrados. Pero, o la arquitectura no tiene nada que decir en este caso (algo que a todas luces no es razonable, dada la envergadura de los retos constructivos que estos edificios han afrontado), o nos encontramos - efectivamente- con una disolución tipológica derivada de la sustitución del verdadero simbolismo por la metáfora o la analogía más o menos ingeniosas (el pez, la barca, el redil...), que si bien son asumibles en una arquitectura efímera, no lo son en un edificio permanente. Un simbolismo que todavía existía en los grandes contenedores que se construyeron en la Antigüedad para alojar peregrinos - la catedral de Santiago de Compostela, la basílica de San Pedro del Vaticano o la de Guadalupe eran y son iglesias en el sentido más arquitectónico de la palabra-y que es urgente recuperar.

Necesitamos volver a estudiar detenidamente la riquísima producción arquitectónica que ha fundamentado la identidad de las iglesias católicas a lo largo de dos milenios. Y a partir de ahí, incorporar a los nuevos usos espaciales el profundo simbolismo que tiene su origen en los ritos de consagración de una iglesia o de dedicación de un altar, por ejemplo.

Pienso que la evolución de la arquitectura religiosa, tanto de la temporal como de la permanente, tanto de la abierta como de la cerrada, dependerá en gran medida de la capacidad de la comunidad de los creyentes - sus usuarios- para asumir los códigos simbólicos que se encuentran en la Liturgia de la Iglesia. Sólo de esta forma podrán exigir a los arquitectos su inserción creativa en las nuevas propuestas que, en el futuro, acabarán por definir su identidad. 


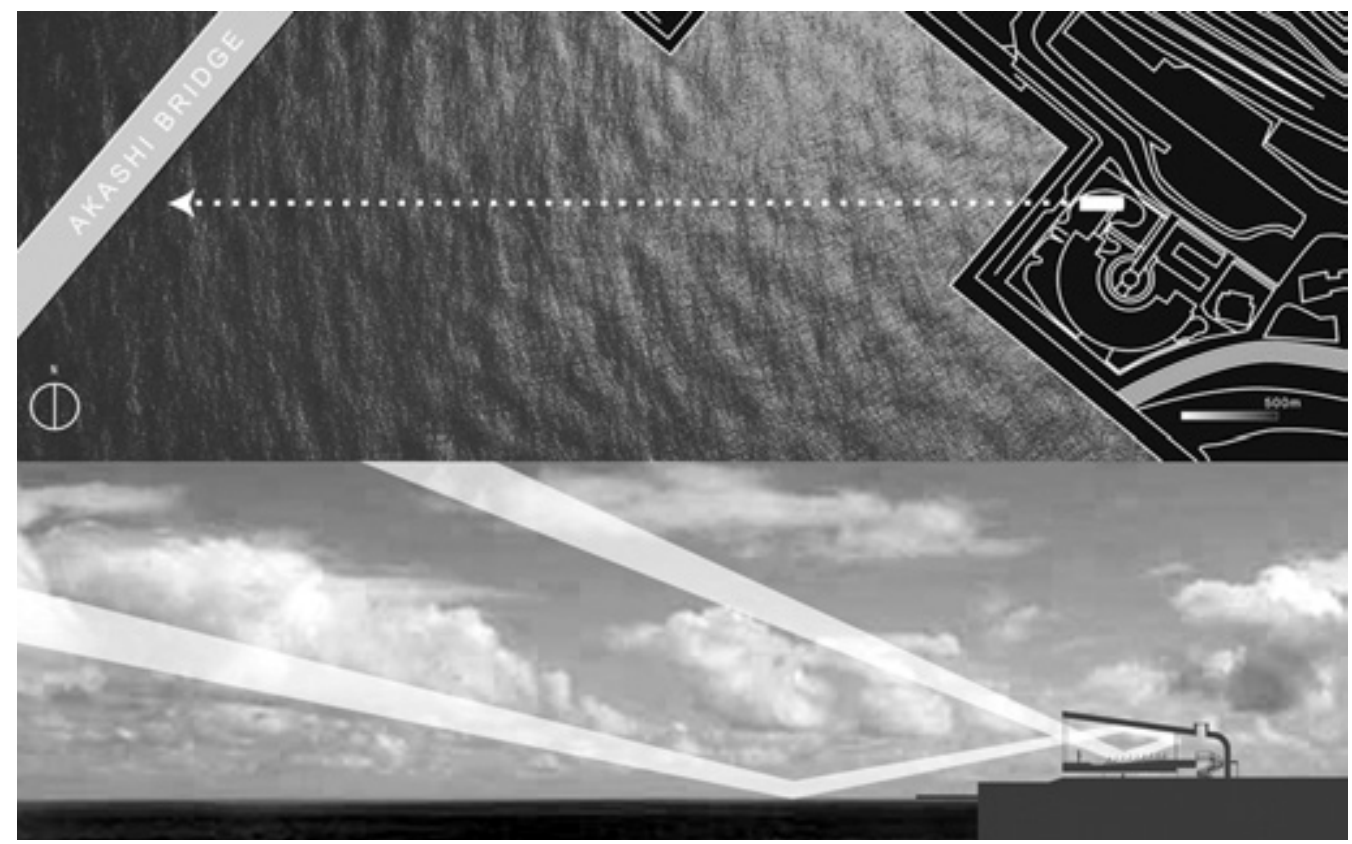

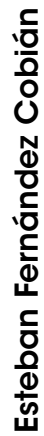

Figs. 14. Ryuichi Ashizawa, Setre Chapel, Kobe (Japón), 2004/05.
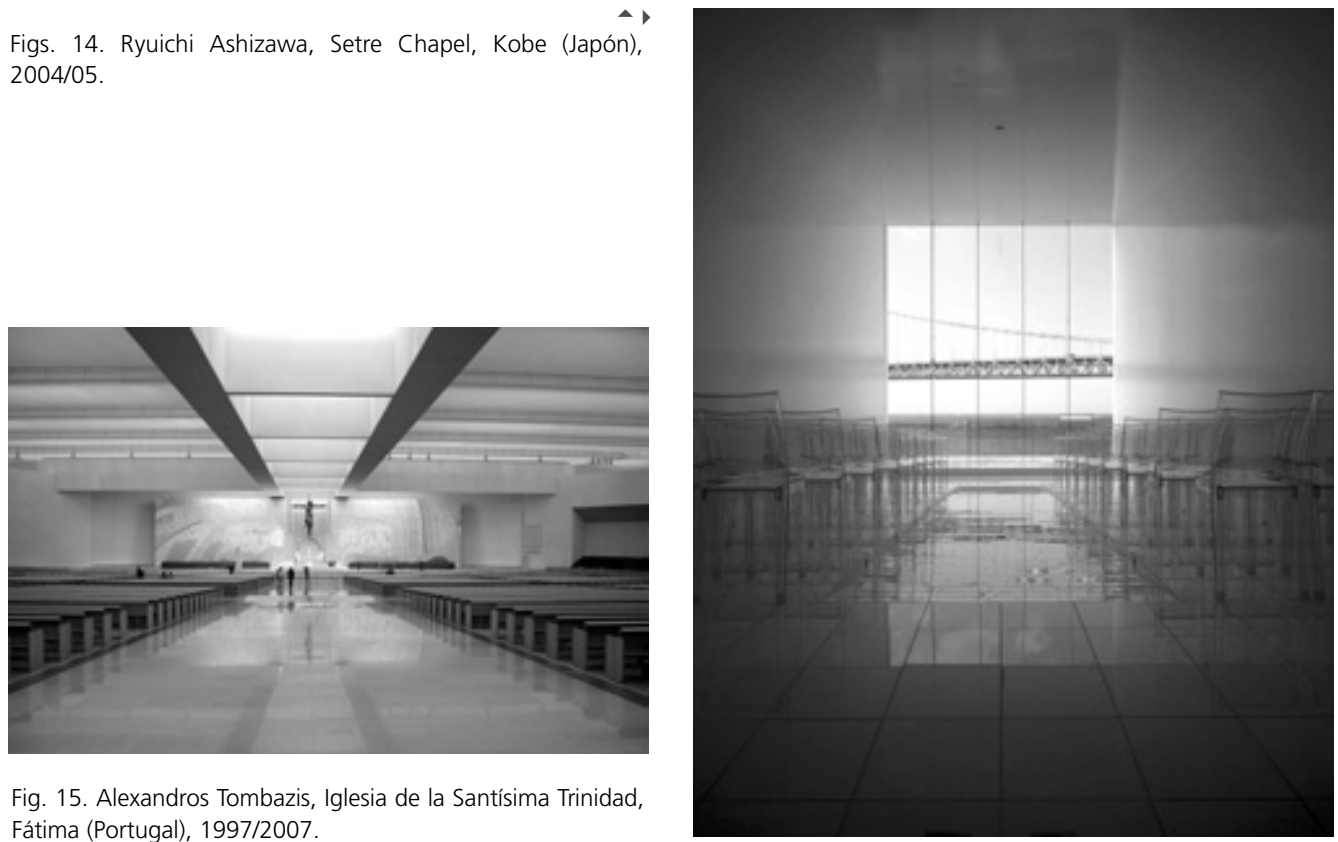

Fig. 15. Alexandros Tombazis, Iglesia de la Santísima Trinidad, Fátima (Portugal), 1997/2007. 


\section{NOTAS}

Cf. Jean-Marie Duthilleuil, «Aménagement liturgique du stade de Longchamp», en: Varios autores, «Églises d'aujourd'hui. Patrimoine de demain» [Actas del congreso], CLD, París, 1997, pág. 88-91. Tras la visita de Juan Pablo II a España en noviembre de 1982, la revista «Arquitectos» publicó un artículo que ilustraba una selección de los altares construidos para la ocasión, esperando tratar el tema más ampliamente en números posteriores. Pero los demás altares nunca se llegaron a publicar (cf. Sa., «Arquitecturas efímeras para un viaje papal», Arquitectos 62 (1982), pág. 11 y 22-29).

Por lo demás, la bibliografía más reciente sobre arquitectura religiosa contemporánea apenas se refiere a este problema. Puede verse, por ejemplo: Esteban Fernández Cobián (coord.), «Arquitecturas de lo sagrado. Memoria y proyecto» [Actas del I Congreso Internacional de Arquitectura Religiosa Contemporánea, Ourense 27-29 de septiembre de 2007], NetBiblo, A Coruña, 2009; Rudolf Stegers, "Sacred Buildings. A design manual», Birkhäuser, Basel/Boston/Berlin, 2008; Richard Kieckhefer, "Theology in Stone: Church Architecture from Byzantium to Berkeley», Oxford University Press, New York, 2004; Wolfgang Jean Stock «Europaischer Kirchenbau, 1950-2000», Prestel, Munich, 2002; Adriano Cornoldi (coord.), «L'architettura dell'edificio sacro», Officina Edizioni, Roma, 1995.

${ }^{2}$ Colexio Oficial de Arquitectos de Galicia, Santiago de Compostela, 2005, pág. 435-455.

${ }^{3}$ Cf. Decio Tozzi y Midori Hatanaka, «Arquiteto Decio Tozzi», DAuria, São Paulo, 2005, pág. 224-237.

${ }^{4}$ Cf. Lucio Costa, «Lucio Costa. Registro de uma vivência», Empresa das Artes, São Paulo, 1995

${ }^{5}$ Aunque, según se desprende del canon 1154 del Código de Derecho Canónico de 1917, en un principio la consagración y la bendición pueden parecer equivalentes a efectos de convertir en sagrados los lugares, en realidad para consagrar siempre se utilizan óleos, mientras que para bendecir se emplea el agua. Es fácil captar la intención de este simbolismo, pues como se sabe, las marcas hechas con aceite son mucho más duraderas que las realizadas con agua.

${ }^{6}$ Cf. «Código de Derecho Canónico y legislación complementaria», BAC, Madrid, 1952 (1917), pág. 312.

7 Ibídem., c. 1197, pág. 446. El Código de Derecho Canónico de 1983 no es tan explícito cuando trata estas cuestiones (c. 1235-1239).

${ }^{8}$ Cf. "Acta Apostolicae Sedis», XXI (1929), pág. 631; citado en: «Código de Derecho Canónico y legislación complementaria», op. cit., pág. 313-nota.

${ }^{9}$ Entre la extensa bibliografía que existe sobre este tema citaremos los textos de Georges Kubler, "Arquitectura mexicana del siglo $\mathrm{XVl}$ », Fondo de Cultura Económica, México, 1992; Juan Bautista Artigas, "Capillas abiertas aisladas de México», UNAM, MéxiCo, 1992; Manuel Castillo Negrete "Las capillas abiertas de la Nueva España», ARA (Madrid), 6/7 (1965/ 66), pág. 50-55; y de Óscar Armando García Gutiérrez, «Fray Toribio Motolinía: la visión urbana de un cronista novohispano. Breve semblanza sobre el diseño de los espacios urbanos y religiosos en Tlaxcala durante el siglo $X V \mid »$, Anales de Literatura Española, 13 (1999), págs. 13-27.

Por su parte, Antonio Bonet Correa puso en relación estas capillas con la arquitectura española en su ya clásico artículo "Antecedentes españoles de las capillas abiertas hispanoamericanas», Revista de Indias (Madrid), 91-92 (1963), págs. 269280, que más tarde continuaría Alfredo José Morales Martínez con su artículo «Nuevos datos sobre capillas abiertas españolas», publicado en: Bibiano Torres Ramírez y José J. Hernández Palomo (coord.), «Andalucía y América en el siglo XVI: actas de las II Jornadas de Andalucía y América» (vol. 2), Consejo Superior de Investigaciones Científicas/Escuela de Estudios Hispanoamericanos, 1983, pags. 453466.

${ }^{10} \mathrm{Cf}$. Varios autores, «Proyecto de Catedral en Madrid. Sesión de Crítica de Arquitectura», Revista Nacional de Arquitectura, 123 (1952), pág. 50.

${ }^{11}$ Cf. Eduardo Junyent i Subirá, «La Iglesia. Construcción. Decoración. Restauración», Balmes, Barcelona, 1940, pág. 18; Ludwig Eisenhofer, "Compendio de liturgia católica», Herder, Barcelona, 1948, pág. 237. El Código de Derecho Canónico de 1917 se refería explícitamente a la separación entre lo sagrado y lo profano (c. 1164), pero siempre aludiendo a dependencias interiores (conexiones visuales con habitaciones, etc.). No parece que hubiera dudas sobre el cerramiento exterior.

12 Entre ellos, me gustaría citar aquí por su concisión y profundidad el trabajo de Jean Hani, «El simbolismo del templo cristiano» (1962), reeditado en sucesivas ocasiones por José J. de Olañeta (Barcelona), la última en 2008.

${ }^{13}$ Intervención de Carlos Castro Cubells, en: Eduardo Amann Garamendi, "Sobre Arquitectura y Liturgia», Hogar y Arquitectura, 57 (1965), pág. 60.

${ }^{14}$ Curiosamente, se trataba de un desarrollo paralelo al preconizado por Francisco Javier Sáenz de Oíza al exponer su proyecto de Capilla en el Camino de Santiago (1955): el triunfo de la energía frente a la masa (cf. Esteban Fernández Cobián, op. cit., pág. 468471).

15 Josemaría Escrivá de Balaguer, «Conversaciones con Mons. Escrivá de Balaguer», Rialp, Madrid, 1969 (3 ed.), pág. 223

${ }^{16}$ Vittorio Messori y Joseph Ratzinger, «Informe sobre la fe», BAC, Madrid, 1986, pág. 18.

${ }^{17}$ En teología, se denomina kerigma al núcleo del mensaje cristiano, a saber: que Jesús de Nazaret es el Mesías esperado, y que su predicación, muerte y resurrección contienen un 
mensaje de libertad para todos los hombres (cf. Lc 4, 18-19 y Hch 2, 22-25).

${ }^{18}$ Literalmente: «Se trabaja para hacer vasijas, pero es del vacío interno del que depende su uso» (Lao-Tse, «Tao-Te-Kin», 550 a.C., nº XI).

${ }^{19} \mathrm{Cf}$. Decio Tozzi y Midori Hata- naka, op. cit., pág. 176-189.

${ }^{20} \mathrm{Cf}$. Giorgio Bonini et al., "Concorso Nazionale pero il complesso di S. Vicenzo de Paoli in Bologna», Chiesa e Quartiere, 2 (1957), pág. 32-54.

${ }^{21}$ Cf. Jean-Marie Duthilleuil, op. cit. 